\title{
EVALUATION OF ANTIBACTERIAL ACTIVITY OF ENDOPHYTIC FUNGI ASPERGILLUS JAPONICUS ISOLATED FROM TRIDAX PROCUMBENS L.
}

\author{
RAVINDRA PRASAD AHARWAL ${ }^{1}$, SUNEEL KUMAR ${ }^{1}$, YOGITA THAKUR ${ }^{2}$, LOKNATH DESHMUKH $^{3}$, SARDUL SINGH \\ SANDHU ${ }^{1 *}$
}

${ }^{1}$ Department of Biological Science, Fungal Biotechnology and Invertebrate Pathology Laboratory, R.D. University, Jabalpur, Madhya Pradesh, India. ${ }^{2}$ Department of Biotechnology, Government Nagarjuna PG College of Science, Raipur, Chhattisgarh, India. ${ }^{3}$ SGH Center for Rural Biotechnology and Management, Jabalpur, Madhya Pradesh, India. Email: ssandhu@rediffmail.com

Received: 23 July 2017, Revised and Accepted: 21 May 2018

ABSTRACT

Objective: The main purpose of the present study was to isolate the endophytic fungi from Tridax procumbens L. and evaluate their antibacterial activity at different concentration of compatible solvents extracted metabolites against the test pathogenic bacterial strain, as well as the molecular characterization of potent endophytic fungal isolate that showed the maximum antibacterial activity.

Methods: The endophytic fungi were isolated from the different parts of the collected T. procumbens plant. Screening of endophytic fungi for the antibacterial activity was scrutinized against five pathogenic bacteria such as Bacillus subtilis, Streptococcus pyogenes, Escherichia coli, Klebsiella pneumoniae, and Salmonella typhimurium using agar well diffusion method. After screening, the metabolite of the potent fungal isolate was extracted using different solvents by solvent-solvent extraction procedure and observed their antibacterial activity. For molecular identification of the fungi, the DNA was extracted, quantified, and amplified using two oligonucleotide primers ITS4 and ITS6 in polymerase chain reaction.

Results: In the present study, five endophytic fungi were isolated from medicinal plant T. procumbens and screened for their antibacterial activity against E. coli $(22.60 \pm 0.32 \mathrm{~mm})$, S. typhimurium $(19.26 \pm 0.23 \mathrm{~mm})$, S. pyogenes $(16.36 \pm 0.18 \mathrm{~mm})$, K. pneumoniae $(14.26 \pm 0.54 \mathrm{~mm})$, and B. subtilis $(14.43 \pm 0.27 \mathrm{~mm})$ bacterial strain. The endophytic fungal strain A. japonicus isolated from T. procumbens was showed the significant antibacterial activity against the pathogenic bacteria. The morphological identification of all the isolated endophytic fungi was observed on the basis of their macroscopic and microscopic characteristics, and the molecular identification of the potent fungal strain was observed through 18s rRNA sequence analysis. Using solvent-solvent extraction technique, different solvent residues of the potent fungal metabolite were extracted in benzene, $\mathrm{n}$-,butanol and toluene. The n-butanol solvent extract exhibited a maximum zone of inhibition against the test bacterial strains.

Conclusion: The present study reveals that the endophytic fungi serve as a potential source for the production of effective bioactive compounds.

Keywords: Antibacterial activity, n-Butanol extract, Tridax procumbens L., Bioactive compounds.

(C) 2018 The Authors. Published by Innovare Academic Sciences Pvt Ltd. This is an open access article under the CC BY license (http://creativecommons. org/licenses/by/4. 0/) DOI: http://dx.doi.org/10.22159/ajpcr.2018.v11i9.21564

\section{INTRODUCTION}

As the population of the world are increased, it is suffering from various health problems caused by certain drug resistance bacteria, parasite protozoans, and fungi. Therefore, an intensive search for the development and invention of new effective agents to deal with these problems is now underway [1]. Since ancient times, people had exploded the nature, particularly, plants in search of new drugs. This has resulted in use of a large number of medicinal plants with curative properties which help in the treatment of various diseases caused by microorganisms [2]. A number of research observed that there are a number of endophytic fungi present inside the plants and protect their host from insects and other herbivores. The term endophyte refers to the group of microorganisms which is part of its life cycle, invades the tissue of living plants, and causes asymptomatic infection [3]. Endophytic fungi have been reported to produce similar compounds to that of the host, and it was confirmed when taxol was obtained from an endophytic fungi isolated from Taxus brevifolia [4]. Endophytic fungi are source of bioactive compounds which have wide range of application in pharmaceutical and agrochemical [5-7]. Bioactive compounds isolated from endophytic fungi belong to several classes such as alkaloids, peptides, steroids, and phenol [6]. These fungi produce novel antibacterial, anticancer, antiviral, antioxidant, insecticidal, and antimalarial compounds that can be utilized by pharmaceutical industries [8,9]. Sandhu et al. [10] isolated the endophytic fungi from Calotropis procera (Linn.) R. Br. of Jabalpur region and tested their antibacterial activity against Klebsiella pneumoniae, Bacillus subtilis, Escherichia coli, Staphylococcus epidermidis, and Pseudomonas aeruginosa. Therefore, in the present investigation, the endophytic fungi were isolated from the medicinal plant Tridax procumbens and observed their antibacterial activity against the pathogenic bacteria.

\section{MATERIALS AND METHODS}

\section{Collection of plant sample}

In the present investigation, the mature and healthy plant leaves were collected from the medicinal plant T. procumbens from Majholi region, Jabalpur (M.P.), India. Plant leaves were collected in sterilized polythene bags and processed for the isolation of endophytic fungi within $12 \mathrm{~h}$ after collection. Plant specimen has been identified/authenticated by respective floras [11-13].

\section{Isolation of endophytic fungi}

The collected fresh leaves were rinsed in running tap water to remove dust and debris. Rinsed leaves were selected for surface disinfection under aseptic condition. The leaves were cut into 3-4 mm diameter segments and surface disinfected in sterilized distilled water for 1-2 min, then treated with $4 \%$ sodium hypochlorite $(\mathrm{NaOCl})$ for 2 min and immersed in $70 \%$ ethanol for $2 \mathrm{~min}$, and again washed in sterilized distilled water for 2 min in laminar airflow. After that, the segments were placed onto the sterilized filter paper for dry and then transferred into Potato Dextrose Agar (PDA) medium Petri plates and incubated 
in fungal incubator at $26 \pm 1^{\circ} \mathrm{C}$ for $5-7$ days. The pure colonies of the endophytic fungi were further transferred on the PDA plates at $26 \pm 1^{\circ} \mathrm{C}$ for 5-7 days. The pure cultures of the isolated fungi were preserved on PDA slant without antibiotic at $4^{\circ} \mathrm{C}$.

\section{Phenotypic identification of isolated endophytic fungi}

The morphological identification of the isolated fungi was done by slide culture technique given by Aggarwal and Hasija, 1980 [14], and Domsch et al. 2007 [15]. The endophytic fungi were characterized on the basis of their color, size and shape of spores, hyphae characters, and reproductive structures [16].

\section{Source of test bacterial strain}

The pathogenic bacteria used in the study such as Salmonella typhimurium microbial type culture collection (MTCC) 733, E. coli MTCC 1679, Staphylococcus aureus MTCC 96, B. subtilis MTCC 441, and K. pneumoniae MTCC 4032 cultures were obtained from MTCC and GenBank, Institute of Microbial Technology (IMTECH), Chandigarh, India. The organisms were preserved at $4^{\circ} \mathrm{C}$ in the presence of glycerol $(15 \% \mathrm{v} / \mathrm{v})$ for longer periods.

\section{Screening of isolated endophytic fungi}

The isolated endophytic fungi were subcultured in Petri plates containing PDA and incubated in a fungal incubator for 6-7 days at $26 \pm 1^{\circ} \mathrm{C}$. Sterile cork borer of $8 \mathrm{~mm}$ was used to cut the portion of mycelia mat and transferred to $100 \mathrm{~mL}$ pre-sterile PDB and incubated at $26 \pm 1^{\circ} \mathrm{C}$ in a fungal incubator for $7^{\text {th }}, 14^{\text {th }}$, and $21^{\text {st }}$ day [17]. Under aseptic conditions, the metabolized broths were filtered by Whatman filter paper no. 1 and centrifuged at $8000 \mathrm{rpm}$ for $8 \mathrm{~min}$. The pellet was discarded and the supernatant refiltered to get cell-free culture filtrate (CFCF) for the estimation of antibacterial activity.

\section{Molecular identification of potent fungi}

After screening, the molecular identification of potent fungal strain was performed by $18 \mathrm{~S}$ rRNA sequence analysis. For the molecular identification, the DNA of potent fungal was isolated by LETS method [18]. In this method, loop full conidia were inoculated to the $10 \mathrm{~mL}$ media and that was incubated for 16-30 h. After that, the mycelia was harvest, washed with distilled water, and lyophilized by liquid nitrogen and crushed in a motor-pastel by adding $0.7 \mathrm{~mL}$ extraction LETS buffer ( $0.1 \mathrm{M} \mathrm{LiCl}, 10 \mathrm{~mm}$ EDTA, $10 \mathrm{~mm} \mathrm{HCL} \mathrm{[pH} \mathrm{8],} \mathrm{and} 0.5 \%$ SDS). After that, crushed mycelia was poured in the centrifuge tubes and vortex for few minutes. After that, $1 \mathrm{~mL}$ phenol:chloroform:isoamyl alcohol (25:24:1) were added and vortexed for $1 \mathrm{~min}$ at medium speed and centrifuged at $3000 \mathrm{rpm}$ for $5 \mathrm{~min}$. There were two layers formed in the tube as aqueous layer and pellet. The pellet was discarded and the aqueous layers was transferred in the other sterilized tube and add $1 \mathrm{~mL}$ absolute chilled ethanol in the aqueous layer and placed the tube on dry ice for $15 \mathrm{~min}$. After that spinned for $15 \mathrm{~min}$ in a microcentrifuge at 10,000 rpm for $10 \mathrm{~min}$. The supernatant was removed and the pellet dissolved in TE buffer for further use.

\section{Quantification and amplification of fungal DNA}

The quantity of the isolated DNA was checked in ultraviolet (UV)visible spectrophotometer. From the stock, $1 \mu \mathrm{L}$ DNA was mixed with $49 \mu \mathrm{L}$ sterile distilled water to get 50 times dilution. The A260/280 was recorded to check the purity of DNA. Polymerase chain reaction (PCR) amplification of ITS region was done in $20 \mu \mathrm{L}$ of reaction mixture containing PCR buffer, $\times 1$ (Kappa, SA); $\mathrm{MgCl}_{2}, 3 \mathrm{mM}$; dNTP mix, 0.25 $\mathrm{mM}$; Taq DNA polymerase, $0.05 \mathrm{U}$; primer, 1 picomol and template DNA, $50 \mathrm{ng}$. Sterile nuclease-free water is used as negative control. The oligonucleotide primers used for PCR amplification are ITS4 and ITS6. The 5'-3' sequence for ITS4 is TCC TCC GCT TAT TGA TAT G, with $50 \mathrm{GC} \%, 51.0^{\circ} \mathrm{C}$ Tm value, and $19 \mathrm{bp}$ length and $700 \mathrm{bp}$ product size. Similarly, the 5'-3' sequence for ITS6 is GAA GGT GAA GTC GTA ACA AGG, with $60 \mathrm{GC} \%, 56.0^{\circ} \mathrm{C}$ Tm value, and 21 bp length. Approximately 50 ng genomic DNA was used as the template for amplification. The temperature conditions were as follows: Initial denaturation at $94^{\circ} \mathrm{C}$ for $2 \mathrm{~min}$, followed by 30 cycles of denaturation at $94^{\circ} \mathrm{C}$ for $50 \mathrm{~s}$, annealing at $48^{\circ} \mathrm{C}$ for $30 \mathrm{~s}$, and extension at $72^{\circ} \mathrm{C}$ for 1 min $30 \mathrm{~s}$. The reactions were optimized for each individual sample; the range of temperatures found to be useful was $48^{\circ} \mathrm{C}$ with $1^{\circ} \mathrm{C}$ increments in annealing temperature until satisfactory amplification was observed. The presence of a single product between $700 \mathrm{bp}$ was verified by agarose gel electrophoresis. The remaining PCR product $(90 \mu \mathrm{L})$ was purified for subsequent manipulations using a QIA-quick-spin PCR purification column (Qiagen), following the manufacturer's protocol. Phylogenetic tree analysis was performed using the MEGA software version 4.0.

\section{Fermentation and extraction}

The PDB medium was inoculated with conidial suspension of the potent endophytic fungal prepared from the 7-day-old culture in sterilized distilled water and incubated the flask at $26 \pm 1^{\circ} \mathrm{C}$ in fungal incubator for 14 days under stationary condition. After fermentation, broth was filtered with the help of Whatman filter paper no. 1 and the CFCF was centrifuged in cooling centrifuge (REMI) at 10,000 rpm for $10 \min \left(4^{\circ} \mathrm{C}\right)$ to remove the cell debris. The separated supernatant was further subjected to solvent extraction using different solvents in the order of their increasing polarity such as toluene, benzene, and n-butanol by solvent-solvent extraction procedure. In this method, the metabolites was dissolved in the solvent, and then, it was taken in separating funnel, shaken vigorously for $15 \mathrm{~min}$, and kept stationary 15-20 min to separate organic phase from aqueous phase. The upper layer was separated and collected in another flask, and the solvent extracts were evaporated in Rotary Vacuum Evaporator (Buchi R-300 Rota-vapor, Buchi Co. Germany). The extract residue was dissolved in double-distilled water and stored at $4^{\circ} \mathrm{C}$ to be used as stock solution for antibacterial activity.

\section{In vitro antibacterial activity by agar well diffusion method}

For antibacterial activity, agar well diffusion method was performed given by Newyork, 1972 [19]. Nutrient agar medium (NAM) plates were prepared and $25 \mu \mathrm{L}$ of bacterial suspension was spread out with the help of glass spreader on the NAM plates to make bacterial lawn and allowed to dry for $10 \mathrm{~min}$. The agar wells were prepared by scooping out the medium with a sterile cork borer which had $8 \mathrm{~mm}$ diameter. The wells were then filled with $75 \mu \mathrm{L}$ of the fungal crude extract and incubated at $37^{\circ} \mathrm{C}$ for $24 \mathrm{~h}$. After the incubation period, the zone of inhibition was measured using HiMedia antibiotic zone scale and compared with the control. All experiments were performed in triplicate.

\section{Statistical analysis}

In the present study, antibacterial activity was conducted in triplicate and the results were calculated as mean $( \pm)$ standard deviation. Data were analyzed with one-way ANOVA and significant differences between mean values at $\mathrm{p}<0.05$ were determined using SPSS program (16.0 versions).

\section{RESULTS}

Isolation and phenotypic identification of isolated endophytic fungi

In the present investigation, five endophytic fungi were isolated from leaves of T. procumbens collected from Majholi, Jabalpur (M.P.), India, as shown in Table 1. Identification of fungal strains was done using standard protocol of Aggarwal and Hasija, 1980 [14], and Domsch et al. 2007 [15]. On the basis of their cultural and microscopic properties, these fungi show different characteristics and successfully identified as Aspergillus japonicus (SG1), Aspergillus niger (SG2), Alternaria sp. (SG3), Fusarium sp. (SG4), and Penicillium sp. (SG5) as shown in Fig. 1.

\section{Screening of isolated endophytic fungi from the plant}

For screening the antibacterial activity of isolated endophytic fungi from the leaves of plant, all fungal isolates were inoculated in PDB for $7^{\text {th }}, 14^{\text {th }}$, and $21^{\text {st }}$ day and incubated at $26 \pm 1^{\circ} \mathrm{C}$ in a fungal incubator. During the screening of endophytic fungi, CFCF of $7^{\text {th }}, 14^{\text {th }}$, and $21^{\text {st }}$ day were examined for their antibacterial activity against the test bacterial strain as shown in Fig. 2 and depicted in Table 2. 
Table 1: Phenotypic characteristics of isolated endophytic fungi from leaves of $T$. procumbens

\begin{tabular}{|c|c|c|c|}
\hline Fungal isolate & Macroscopic characteristic & Microscopic characteristic & Probable genera/species \\
\hline SG1 & $\begin{array}{l}\text { Colony wrinkled, near mummy brown, } \\
\text { mycelium white, reverse uncolored }\end{array}$ & $\begin{array}{l}\text { Conidial heads radiate, hyaline to pale brown, smooth, } \\
\text { vesicles subglobose to globose, conidia spherical or } \\
\text { ellipsoidal }\end{array}$ & Aspergillus japonicus \\
\hline SG2 & $\begin{array}{l}\text { Colonies were powdery in texture and } \\
\text { black in color with conidial production, } \\
\text { reversed plate showed pale yellow } \\
\text { colored due to pigmentation }\end{array}$ & $\begin{array}{l}\text { Hyphae septate hyaline dichotomously branched } \\
\text { vesicle, round, radiate head, black conidia, spores erect, } \\
\text { simple and thick walled }\end{array}$ & Aspergillus niger \\
\hline SG3 & $\begin{array}{l}\text { Woolly colonies greenish-black or olive } \\
\text { brown with a light border }\end{array}$ & $\begin{array}{l}\text { Single conidia, smooth-wall, dark in color, septate } \\
\text { hyphae }\end{array}$ & Alternaria sp. \\
\hline SG4 & $\begin{array}{l}\text { White pink color, smooth swarming and } \\
\text { raised colony }\end{array}$ & $\begin{array}{l}\text { Multi-celled spores, conidia are oval shaped and attached } \\
\text { to conidiophores arising from a septate mycelium }\end{array}$ & Fusarium sp. \\
\hline SG5 & White and cottony colonies & $\begin{array}{l}\text { Single-celled spores, conidia in chains develop at } \\
\text { the end of the sterigma from the medulla of the } \\
\text { conidiophores arise from a septate mycelium }\end{array}$ & Penicillium sp. \\
\hline
\end{tabular}

Table 2: Screening of isolated endophytic fungi against five pathogenic bacteria

\begin{tabular}{|c|c|c|c|c|c|c|}
\hline \multirow[t]{2}{*}{ Name of fungi } & \multirow[t]{2}{*}{ Day of incubation period } & \multicolumn{5}{|c|}{ Zone of inhibition (in mm) } \\
\hline & & B. subtilis & S. pyogenes & E. coli & S. typhimurium & K. pneumoniae \\
\hline \multirow[t]{3}{*}{ A. japonicus } & 07 & $00.00 \pm 0.00$ & $00.00 \pm 0.00$ & $06.11 \pm 0.54$ & $00.00 \pm 0.00$ & $00.00 \pm 0.00$ \\
\hline & 14 & $14.43 \pm 0.27$ & $16.36 \pm 0.18$ & $22.60 \pm 0.32$ & $19.26 \pm 0.23$ & $14.26 \pm 0.54$ \\
\hline & 21 & $08.31 \pm 0.54$ & $00.00 \pm 0.00$ & $08.16 \pm 0.47$ & $00.00 \pm 0.00$ & $00.00 \pm 0.00$ \\
\hline \multirow[t]{2}{*}{ Fusarium sp. } & 07 & $05.05 \pm 0.39$ & $00.00 \pm 0.00$ & $07.23 \pm 0.58$ & $00.00 \pm 0.00$ & $00.00 \pm 0.00$ \\
\hline & 14 & $14.76 \pm 0.55$ & $00.00 \pm 0.00$ & $16.33 \pm 0.35$ & $13.56 \pm 0.20$ & $16.53 \pm 0.33$ \\
\hline \multirow[t]{3}{*}{ Alternaria sp. } & 07 & $00.00 \pm 0.00$ & $12.24 \pm 0.26$ & $10.00 \pm 0.17$ & $00.00 \pm 0.00$ & $07.15 \pm 0.32$ \\
\hline & 14 & $09.56 \pm 0.45$ & $09.40 \pm 0.26$ & $10.53 \pm 0.25$ & $00.00 \pm 0.00$ & $09.56 \pm 0.36$ \\
\hline & 21 & $11.04 \pm 0.19$ & $00.00 \pm 0.00$ & $13.23 \pm 0.36$ & $08.04 \pm 0.72$ & $06.16 \pm 0.14$ \\
\hline \multirow[t]{3}{*}{ A. niger } & 07 & $13.71 \pm 0.28$ & $09.22 \pm 0.42$ & $17.32 \pm 0.25$ & $00.00 \pm 0.00$ & $12.24 \pm 0.58$ \\
\hline & 14 & $08.50 \pm 0.22$ & $06.05 \pm 0.47$ & $12.23 \pm 0.54$ & $10.06 \pm 0.46$ & $00.00 \pm 0.00$ \\
\hline & 21 & $08.32 \pm 0.54$ & $00.00 \pm 0.00$ & $10.20 \pm 0.31$ & $00.00 \pm 0.00$ & $00.00 \pm 0.00$ \\
\hline \multirow[t]{2}{*}{ Penicillium sp. } & 07 & $00.00 \pm 0.00$ & $12.04 \pm 0.56$ & $07.08 \pm 0.38$ & $00.00 \pm 0.00$ & $00.00 \pm 0.00$ \\
\hline & 14 & $11.30 \pm 0.09$ & $08.40 \pm 0.23$ & $16.36 \pm 0.47$ & $10.02 \pm 0.80$ & $00.00 \pm 0.00$ \\
\hline
\end{tabular}

A. japonicus: Aspergillus japonicus, A. niger: Aspergillus niger, B. subtilis: Bacillus subtilis, S. pyogenes: Streptococcus pyogenes, E. coli: Escherichia coli, K. pneumoniae: Klebsiella pneumoniae, S. typhimurium: Salmonella typhimurium

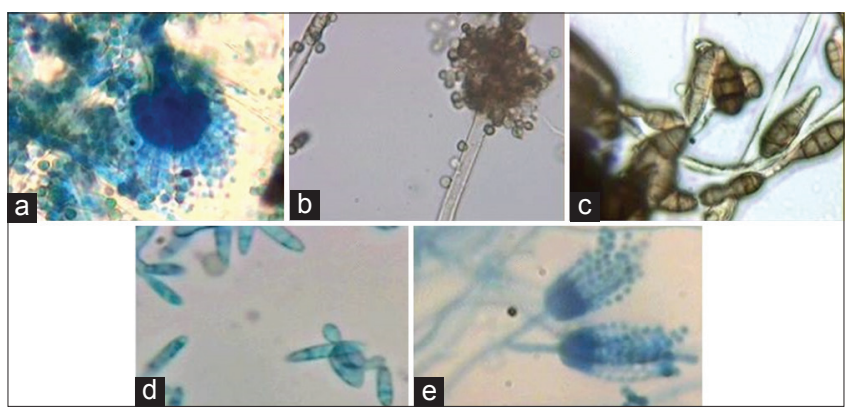

Fig. 1: Light microscopic $(\times 40)$ observation of endophytic fungi (a): SG1 - Aspergillus japonicus, (b) SG2 - Aspergillus niger, (c) SG3 - Alternaria sp., (d) SG4 - Fusarium sp., (e) SG5 - Penicillium sp.

\section{Molecular identification of potent fungus}

After screening the antibacterial activity of the endophytic fungi, the potent fungal strain A. japonicus was showed and the maximum antibacterial activity against the test bacteria was further identified by molecular sequencing using $18 \mathrm{~S}$ rRNA sequence analysis. In the molecular study, two primers, namely, ITS 4 (TCC TCC GCT TAT TGA TAT G) and ITS6 (GAA GGT GAA GTC GTA ACA AGG) were used for molecular identification. Based on BLAST search of rRNA gene sequence, the endophytic fungi were found to be closest homology to A. japonicus and submitted to the NCBI GenBank with accession no. KY218732 (Fig. 3). Phylogenetic tree was constructed based on the closest relationship with consensus sequences and shown in Fig. 4.

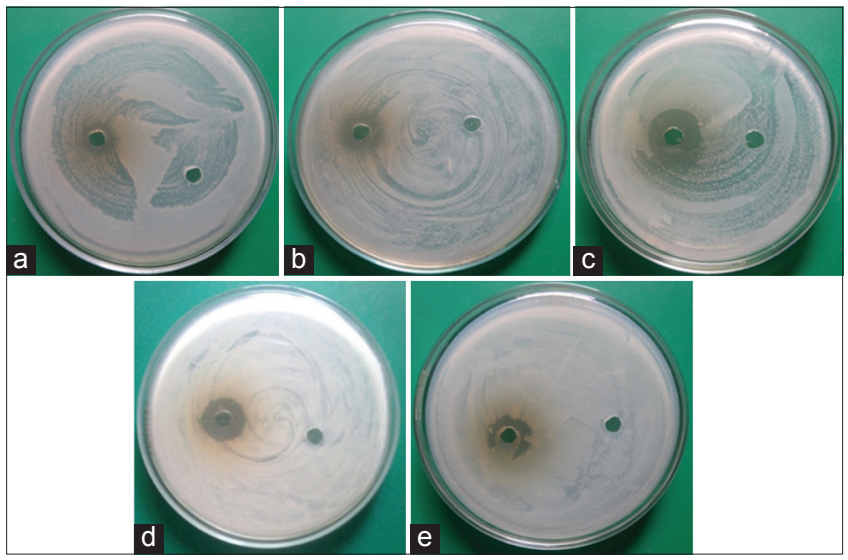

Fig. 2: Antibacterial activity of $\mathbf{1 4}$ days old cell-free culture filtrate of Aspergillus japonicus, (a) Bacillus subtilis, (b) Streptococcus pyogenes, (c) Escherichia coli, (d) Salmonella typhimurium, (e) Klebsiella pneumoniae

\section{In vitro antibacterial activity of potent fungi}

In the present investigation, metabolites of endophytic fungi A.japonicus that showed the maximum zone of inhibition against the test bacterial strain were extracted with a number of organic solvent such as benzene, toluene, and n-butanol $(1: 1 \mathrm{v} / \mathrm{v})$ and concentrated in rotary vacuum evaporator. After evaporation of solvent, the metabolites were mixed 
with sterilized distilled water and observed their antibacterial activity by agar well diffusion method, and the fraction of n-butanol extract was showed maximum antibacterial activity against B. subtilis, E. coli, MTCC1679, K. pneumoniae MTCC4032, S. typhimurium MTCC733, and Streptococcus pyogenes MTCC96 as shown in Table 3. The optimum inhibitory concentration of n-butanol fungal extract was also observed at different concentrations from a range of $25-800 \mu \mathrm{L}$. The antibacterial activity of the n-butanol extract was increased as the concentration was augmented, and after $800 \mu \mathrm{L}$ concentration, the antibacterial activity of the solvent extracted metabolites was fairly stable as depicted in Table 4.

\section{DISCUSSION}

Endophytic fungi are the most promising bioagent that has a huge source of various bioactive compounds. Mainly, these compounds could be classified as alkaloids, terpenoids, quinones, steroids, isocoumarins, saponins, lactones, phenylpropanoids, and phenols [9,20]. Many of these compounds are being used for the treatment of a number of diseases [7]. Thus, in the present work, endophytic fungi were isolated from the medicinal plant T. procumbens $\mathrm{L}$. and observed their antibacterial against the bacterial strain. Sandhu et al. 2016 [21] reported seven endophytic fungi such as Aspergillus niger, Penicillium citrinum, Cladosporium sp., Curvularia lunata, Aspergillus sp., Alternaria sp., and Aspergillus fumigates isolated from Rauwolfia serpentina and the morphological identification was completed based on mycelia type, aerial color, shape and kind of spores, presence of foot cells, conidiophores, and the characteristics of spores. In another study, Tran et al. 2010 [22] isolated six endophytic fungi form phyllodes of Acacia species and molecular identification was done through $18 \mathrm{~S}$ rRNA gene sequencing. In the present study, five endophytic fungal strains were isolated from T. procumbens and identified as Aspergillus japonicus, Fusarium sp., Aspergillus niger, Alternaria sp., and Penicillium sp. using phenotypic characteristics, and the potent fungal strain was identified on the basis of $18 \mathrm{~S}$ rRNA sequencing using ITS 4 and ITS6 primers. Parenicova et al. 2001 [23] used DNA sequence of the ITS1 and ITS2 region to make sure the close relationship between A. japonicus and A. aculeatus. In the present study, phylogenetic tree was constructed and that showed, 99\% similarity with A. Japonicus. During the screening of endophytic fungi, CFCF of $7^{\text {th }}, 14^{\text {th }}$, and $21^{\text {st }}$ day was examined for their antibacterial activity. A. japonicus showed the maximum inhibitory effect against selected pathogenic bacteria. The optimum inhibitory concentration of n-butanol fungal extract was also observed at different concentrations that the antibacterial activity was elevated as the concentration of n-butanol extracted metabolites was increased. Similarly, Meenupriya and Thangaraj, in 2011 [24], also observed the inhibitory concentration of ethyl acetate extract of the Aspergillus ocharaceus against the four pathogenic bacteria from a range of $25-1000 \mu \mathrm{L}$ and the maximum antibacterial activity was examined as the concentration of the solvent extract was increased.

\section{CONCLUSION}

Endophytic fungi are those microorganisms that survive interior of plants an especially leaf, stems, and roots without any apparent harm to host. Endophytes are rich sources of bioactive metabolites, which can be potentially used in the field of medicine, agriculture, and industries. In the present investigation, fungal endophyte $A$. japonicus isolated from T. procumbens showed the maximum antibacterial activity against the test bacterial strain. Further study can be performed to identify the bioactive compounds present in the extract. A. japonicus exhibited the most significant inhibitory activity against five pathogenic bacteria. The isolation of these antibacterial compounds from the endophytic fungi and identification of bioactive compounds can be a crucial approach to search of novel natural products.

\section{ACKNOWLEDGMENTS}

The authors wish to thank the Director of SGHRBM, Mrs. Ranjeet Kaur Sandhu Jabalpur, and the Head, Department of Biotechnology, Government Nagarjuna PG College of Science, Raipur (C.G.), India, for providing laboratory facility.

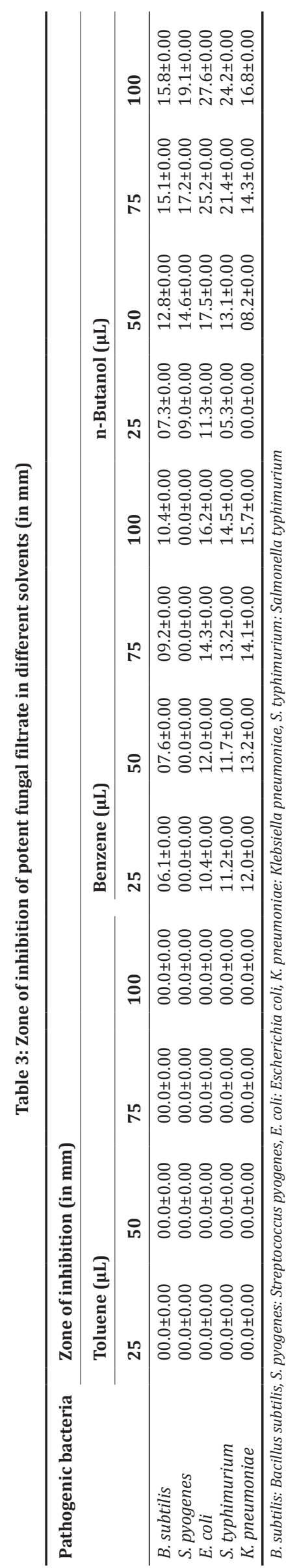


Table 4: Well-diffusion method standardization (n-butanol fungal extract low and high concentration)

\begin{tabular}{|c|c|c|c|c|c|}
\hline \multirow[t]{2}{*}{ Concentration $(\mu \mathrm{L})$} & \multicolumn{5}{|c|}{ Zone of inhibition (in mm) } \\
\hline & B. subtilis & S. pyogenes & E. coli & S. typhimurium & K. pneumoniae \\
\hline \multicolumn{6}{|l|}{ Low concentration } \\
\hline 25 & $07.40 \pm 0.21$ & $09.10 \pm 0.26$ & $11.37 \pm 0.52$ & $05.20 \pm 0.12$ & $00.00 \pm 0.00$ \\
\hline 50 & $12.20 \pm 0.34$ & $14.12 \pm 0.53$ & $17.34 \pm 0.36$ & $13.23 \pm 0.74$ & $08.16 \pm 0.52$ \\
\hline 75 & $15.13 \pm 0.71$ & $17.30 \pm 0.45$ & $25.31 \pm 0.78$ & $21.42 \pm 1.05$ & $14.20 \pm 0.94$ \\
\hline 100 & $15.52 \pm 0.45$ & $19.11 \pm 0.34$ & $27.26 \pm 0.57$ & $24.13 \pm 0.65$ & $16.04 \pm 0.32$ \\
\hline \multicolumn{6}{|l|}{ High concentration } \\
\hline 200 & $17.30 \pm 0.62$ & $22.42 \pm 0.57$ & $29.05 \pm 1.12$ & $26.18 \pm 0.38$ & $19.21 \pm 0.57$ \\
\hline 400 & $19.50 \pm 0.44$ & $23.14 \pm 0.49$ & $30.23 \pm 0.84$ & $27.42 \pm 0.05$ & $21.14 \pm 0.25$ \\
\hline 600 & $20.33 \pm 0.37$ & $24.46 \pm 0.87$ & $31.12 \pm 0.92$ & $28.13 \pm 0.76$ & $22.40 \pm 0.54$ \\
\hline 800 & $20.30 \pm 0.85$ & $25.19 \pm 0.68$ & $31.60 \pm 0.30$ & $29.06 \pm 0.43$ & $23.27 \pm 0.35$ \\
\hline
\end{tabular}

B. subtilis: Bacillus subtilis, S. pyogenes: Streptococcus pyogenes, E. coli: Escherichia coli, K. pneumoniae: Klebsiella pneumoniae, S. typhimurium: Salmonella typhimurium

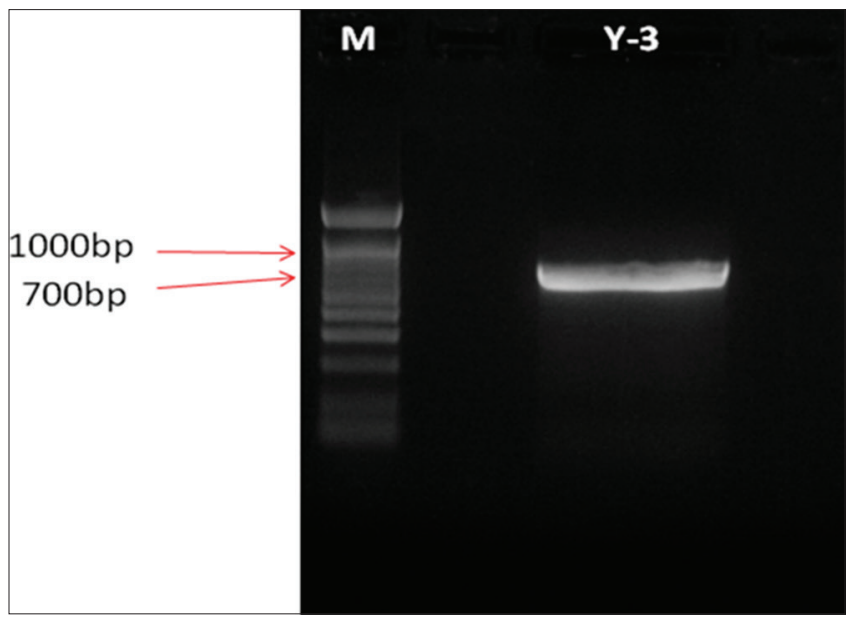

Fig. 3: 1\% Agarose Gel data showing the band of Amplified DNA (700bp),

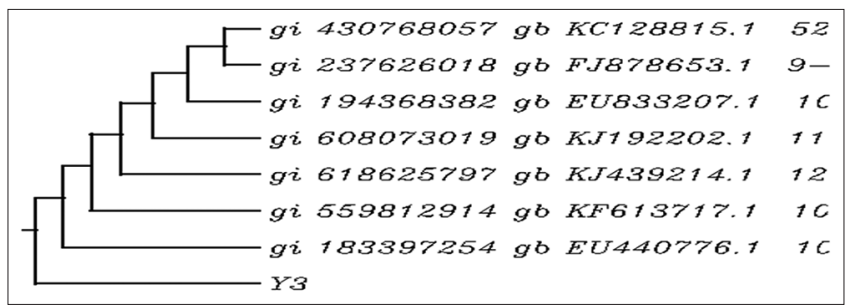

Fig. 4: Phylogenetic analysis of the obtained sequence of ITS Region with Aspergillus japonicas sequences from Genbank

\section{REFERENCES}

1. Wu X, Lu Y, Zhou S, Chen L, Xu B. Impact of climate change on human infectious diseases: Empirical evidence and human adaptation. Environ Int 2016;86:14-23.

2. Godstime OC, Enwa FO, Augustina JO, Christopher EO. Mechanisms of antimicrobial actions of phytochemicals against enteric pathogens - A review. J Pharm Chem Biol Sci 2014;2:77-85.

3. De Bary A. Morphologie and Physiologie der Pilze, Flechten and Myxomyceten, Holfmeister's Handbook of Physiological Botany. Germany: Leipzig; 1866.

4. Strobel G, Yang X, Sears J, Kramer R, Sidhu RS, Hess WM. Taxol from Pestalotiopsis microspora, an endophytic fungus of Taxus wallachiana. Microbiology 1996;142:435-40.

5. Strobel G, Daisy B. Bioprospecting for microbial endophytes and their natural products. Microbiol Mol Biol Rev 2003;67:491-502.

6. Joseph B, Priya RM. Bioactive compound from endophytes and their potential in pharmaceutical effect. Am J Biochem Mol Biol 2011;1:291-309.

7. Sandhu SS, Suneel K, Aharwal RP, Shukla H, Rajak RC. Endophytic fungi: As a source of antimicrobials bioactive compounds. World J Phar Pharm Sci 2014;3:1179-7.

8. Strobel G, Daisy B, Castillo U, Harper J. Natural products from endophytic microorganisms. J Nat Prod 2004;67:257-68.

9. Gouda S, Das G, Sen SK, Shin HS, Patra JK. Endophytes: A treasure house of bioactive compounds of medicinal importance. Front Microbiol 2016;7:1538.

10. Sandhu SS, Aharwal RP, Kumar S. Isolation and antibacterial property of endophytic fungi isolated from Indian medicinal plant Calotropis procera (Linn.). R Br World J Phar Pharm Sci 2014;3:678-91.

11. Verma DM, Balakrishnan NP, Dixit RD. Flora of Madhya Pradesh. Vol. 1. India, Calcutta: BSI Publication; 1993.

12. Oommachans M, Shrivastava JL. Flora of Madhya Pradesh. India, Jodhpur: Scientific Publishers; 1996.

13. Mudgal V, Khanna KK, Hajra PK. Flora of Madhya Pradesh. Vol. 2. India, Calcutta: Botanical Survey of India; 1997.

14. Aggarwal GP, Hasija SK. Microorganisms in the Laboratory: A Laboratory Guide of Mycology, Microbiology and Plant Pathology. Lucknow: Print House; 1980.

15. Domsch KH, Gams W, Anderson TH. Compendium of Soil Fungi. $2^{\text {nd }}$ ed. Germany: IHW-Verlag, Eching; 2007.

16. Barnett HL, Hunter BB. Illustrated Genera of Imperfect Fungi. $4^{\text {th }}$ ed. USA: St. Paul Minnesota APS Press; 1998.

17. Tolulope RA, Adeyemi AI, Erute MA, Abiodun TS. Isolation and screening of endophytic fungi from three plants used in traditional medicine in Nigeria for antimicrobial activity. Int J Green Pharm 2015;9:58-62.

18. Sandhu SS. Recombinant DNA Technology. India, New Delhi: I.K. International Publishing House Pvt. Ltd; 2010.

19. Newyork NY, Barnett HL, Hunter BB. Illustrated Genera of Imperfecti Fungi. Minneapolis: Burgers Company; 1972.

20. Yu H, Zhang L, Li L, Zheng C, Guo L, Li W, et al. Recent developments and future prospects of antimicrobial metabolites produced by endophytes. Microbiol Res 2010;165:437-49.

21. Sahu R, Kumar S, Aharwal RP, Sandhu SS. Antibacterial activity of isolated endophytic fungi from Rauvolfia serpentine (L.) Benth. ex Kurz. Int J Pharm Pharm Sci 2016;8:38-42.

22. Tran HB, McRae JM, Lynch F, Palombo EA. Identification and bioactive properties of endophytic fungi isolated from phyllodes of Acacia species. Curr Res Technol Edu Topics Appl Microbiol Microb Technol 2010;377-82.

23. Parenicova L, Skouboe P, Frisvad J, Samson RA, Rossen L, HoorSuykerbuyk MT, et al. Combined molecular and biochemical approach identifies Aspergillus japonicas and Aspergillus aculeatus as two species. Appl Environ Microbiol 2001;67:521-7.

24. Meenupriya J, Thangaraj M. Analytical characterization and structure elucidation of metabolites from Aspergillus ochraceus MP2 fungi. Asian Pac J Trop Biomed 2011;1:376-80. 